\title{
ERRATUM
}

\section{Redox-induced reversible metal assembly through translocation and reversible ligand coupling in tetranuclear metal sandwich frameworks}

Tetsuro Murahashi, Katsunori Shirato, Azusa Fukushima, Kohei Takase, Tomoyoshi Suenobu, Shunichi Fukuzumi, Sensuke Ogoshi and Hideo Kurosawa

Nature Chemistry http://dx.doi.org/10.1038/nchem.1202 (2011); published online 20 November 2011; corrected online 21 November 2011.

In the version of this Article originally published online, an extraneous Pd atom appeared in Fig. 3. This has now been corrected in all versions of the Article. 